\title{
Neuroprotective Effects of Ginseng Phytochemicals: Recent Perspectives
}

\author{
Xing Huang ${ }^{1,2}$, Ning $\mathrm{Li}^{3,4}$, Yiqiong Pu ${ }^{2}$, Tong Zhang ${ }^{1,2, *}$ and Bing Wang ${ }^{1,5, * \mathbb{C}}$ \\ 1 School of Pharmacy, Shanghai University of Traditional Chinese Medicine, Shanghai 201203, China \\ 2 Experiment Center for Teaching and Learning, Shanghai University of Traditional Chinese Medicine, \\ Shanghai 201203, China \\ 3 Institute of Chinese Materia Medica, Shanghai University of Traditional Chinese Medicine, \\ Shanghai 201203, China \\ 4 Research Institute of KPC Pharmaceuticals, Inc., Kunming 650106, China \\ 5 Center for Pharmaceutics Research, Shanghai Institute of Materia Medica, Chinese Academy of Sciences, \\ Shanghai 201203, China \\ * Correspondence: zhangtdmj@hotmail.com (T.Z.); bwang@simm.ac.cn (B.W.)
}

Academic Editor: David Popovich

Received: 12 July 2019; Accepted: 12 August 2019; Published: 14 August 2019

\begin{abstract}
As our global population ages, the treatment of neurodegenerative diseases is critical to our society. In recent years, researchers have begun to study the role of biologically active chemicals from plants and herbs to gain new inspiration and develop new therapeutic drugs. Ginseng (Panax ginseng C.A. Mey.) is a famous Chinese herbal medicine with a variety of pharmacological activities. It has been used to treat various diseases since ancient times. Extensive research over the years has shown that ginseng has potential as a neuroprotective drug, and its neuroprotective effects can be used to treat and prevent neurological damage or pathologically related diseases (such as Alzheimer's disease, Parkinson's disease, Huntington's disease, depression symptoms, and strokes). Moreover, evidence for the medicinal and health benefits of ginsenoside, its main active ingredient, in the prevention of neurodegenerative diseases is increasing, and current clinical results have not reported any serious adverse reactions to ginseng. Therefore, we briefly review the recent research and development on the beneficial effects and mechanisms of ginseng and its main active ingredient, ginsenoside, in the prevention and treatment of neurodegenerative diseases, hoping to provide some ideas for the discovery and identification of ginseng neuroprotection.
\end{abstract}

Keywords: neuroprotective effects; ginseng; Alzheimer's disease; ginsenoside; Parkinson's disease

\section{Introduction}

As our global population ages, the treatment of neurodegenerative diseases is critical to our society. According to the World Health Organization, the percentage of the world's population over the age of 60 will almost double from $12 \%$ in 2015 to $22 \%$ in 2050, reaching nearly 2 billion by 2050. In developed countries, the prevalence of known age-related neurodegenerative diseases such as Alzheimer's disease (AD) [1] and Parkinson's disease (PD) [2] has increased due to prolonged life expectancy. When it comes to $\mathrm{AD}$, no one is a stranger. It has been more than 100 years since Dr. Alzheimer first described the disease in 1906. However, we have not found any effective means to prevent and treat this disease. Every year, hundreds of thousands of older adults suffer from this degenerative disease. These incurable diseases have devastating effects on patients and their families. Neurodegenerative diseases are mainly divided into chronic neurodegenerative diseases and acute neurodegenerative diseases. The former mainly includes AD, PD, Huntington's disease, and the like. The latter includes mostly cerebrovascular accidents, stroke sequelae, and the like. Besides, depressive symptoms are often 
present in chronic conditions, as are chronic neurodegenerative disorders. Many patients with cognitive decline and dementia caused by AD and PD may have higher or lower levels of depressive symptoms at some point during their illness. Depressive symptoms are of particular importance in neurological diseases, especially in neurodegenerative diseases, because of the relationship between the brain, spirit, behavior, and mood [3]. The same is true of stress. The cause of neurodegenerative diseases as a group of heterogeneous diseases has not been fully elucidated. However, increased oxidative stress, protease resistance misfolding, chronic neuroinflammation, and the accumulation of aggregated proteins have been recognized as common mechanisms of most neurodegenerative diseases [4-6]. Recently, medicinal plants have received much focus, and disease-modifying drugs have been developed that can inhibit or delay the process of neurodegenerative processes [7]. As a well-known and popular Chinese medicine, ginseng has been found to have potential as a neuroprotective agent.

Ginseng is derived from the roots of Panax ginseng Meyer (Araliaceae) and has been used as a medication for thousands of years in East Asian countries, such as Japan, China, and Korea [8]. In China, ginseng has long been used as a drug whose clinical applications are extensive with proper development and utilization value. Ginseng promotes vitality, prolongs life, and shows therapeutic effects against various conditions, such as immune regulation, antitumor, antifatigue, antiaging, antioxidation, depression, diabetes, inflammation, dyspepsia, nervous system diseases, and many other aspects [9-15]. The various pharmacological activities of ginseng are attributed to its various active ingredients, such as ginsenosides, ginseng polysaccharides, volatile oils (terpenoids, alcohols, fatty acids, etc.), peptides, and amino acids $[16,17]$. One study showed that ginsenosides are the main active ingredient of ginseng responsible for its therapeutic and pharmacologic effects [18]. So far, more than 180 species of ginsenosides have been identified, according to reports $[19,20]$. Although all ginsenosides have different chemical structures, four-ring hydrophobic structures are familiar to them [21]. From a chemical viewpoint, these glycosides are classified into the 20(S)-protopanaxadiol type, which contains ginsenosides $\mathrm{Rb} 1, \mathrm{Rc}, \mathrm{Rb} 2, \mathrm{Rd}$, and $\mathrm{Rg} 3$, and the 20(S)-protopanaxatriol group, which includes ginsenosides Rg1, Re, Rg2, and Rh1 depend on different glycosides [22] (Figure 1). In fresh ginseng, $\mathrm{Rb} 2, \mathrm{Rb} 1, \mathrm{Re}, \mathrm{Rg} 1$, and $\mathrm{Rc}$ are the main ginsenosides (70-80\% of total ginsenosides) [23].

Ginsenosides may play a beneficial therapeutic role in some degenerative diseases, such as cardiovascular disease [24], glaucoma [25], cancer [26], and stroke [27-29]. As the main active ingredients of ginseng, 20(S)-protopanaxadiol and 20(S)-protopanaxatriol groups have gradually become the focus of medical and pharmaceutical research. These compounds also show advantageous pharmacological effects in the central nervous system (CNS), which can be converted therapeutically into clinical applications. Ginsenosides can strengthen brain function, prevent neuroinflammation and oxidative stress, and reduce or weaken a variety of neurodegenerative disorders, such as PD, AD, traumatic brain injury, and Huntington's disease (HD) [30-33].

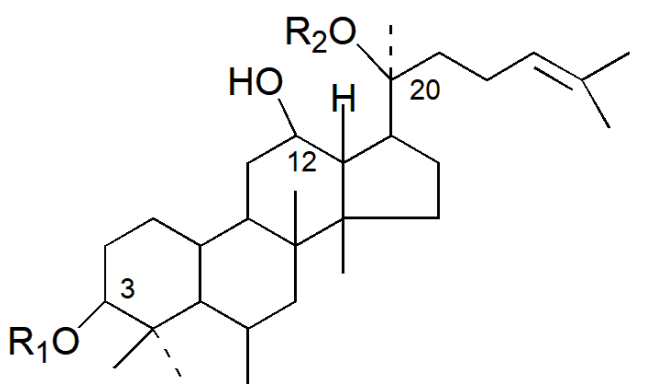

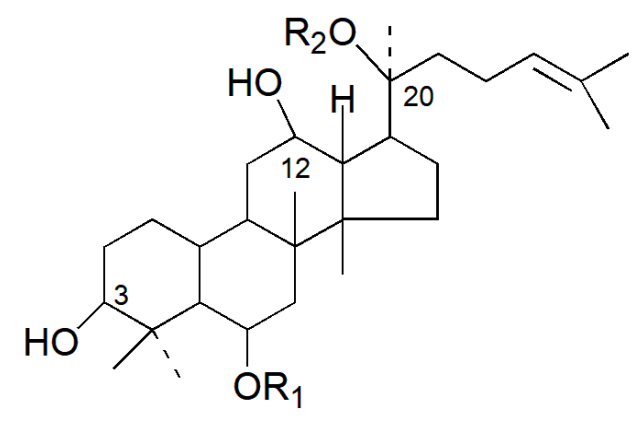

Figure 1. Cont. 


\begin{tabular}{lcc} 
& $\mathbf{R}_{\mathbf{1}}$ & \multicolumn{1}{c}{$\mathbf{R}_{\mathbf{2}}$} \\
$\mathbf{R b}_{\mathbf{1}}$ & glc $(2-1) g l c$ & glc $(6-1) g l c$ \\
$\mathbf{R b}_{\mathbf{2}}$ & glc(2-1)glc & glc(6-1)ara(p) \\
$\mathbf{R c}$ & glc(2-1)glc & glc(6-1)ara(f) \\
$\mathbf{R d}$ & glc(2-1)glc & glc \\
$\mathbf{R g}_{\mathbf{3}}$ & glc(2-1)glc & $\mathrm{H}$ \\
& \\
& \\
glc: glucopyranose \\
ara(f): a-L-arabinose(pyranose) \\
ara(f):a-L-arabinose(furanose) \\
rah: rhambopyranose
\end{tabular}

$\begin{array}{lcc} & \mathbf{R}_{\mathbf{1}} & \mathbf{R}_{\mathbf{2}} \\ \mathbf{R e} & \text { glc }(2-1) \text { rah } & \text { glc } \\ \mathbf{R g}_{1} & \text { glc } & \text { glc } \\ \mathbf{R h}_{\mathbf{1}} & \text { glc } & \mathrm{H}\end{array}$

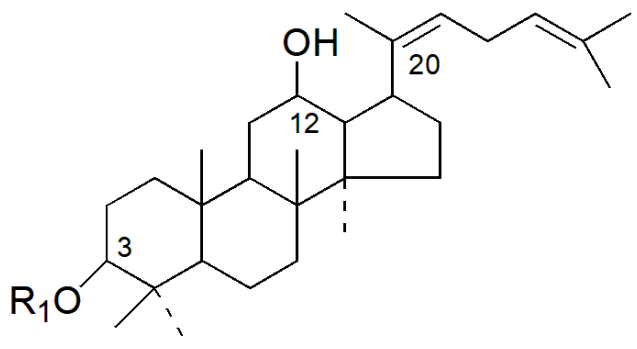

$\mathbf{R}_{\mathbf{1}}$

$\mathrm{Rg}_{5}$ glc-glc

Figure 1. Structures of representative ginsenosides.

Many reviews over the years have demonstrated the neuroprotective effects of ginseng and suggest that ginseng has potential as a therapeutic drug for various degenerative neurological diseases. However, they have extensively reviewed the treatment of ginseng in a certain degenerative nervous system disease [34-36] or covered ginseng treatment in multiple degenerative nervous systems but have not provided an in-depth review $[37,38]$. On the basis of these predecessors, this article comprehensively reviews the latest research and development of the beneficial effects and mechanisms of ginseng and its main active ingredient ginsenoside in the treatment and prevention of neurodegenerative diseases and hopes to discover and identify the neuroprotective effects of ginseng (Figure 2).

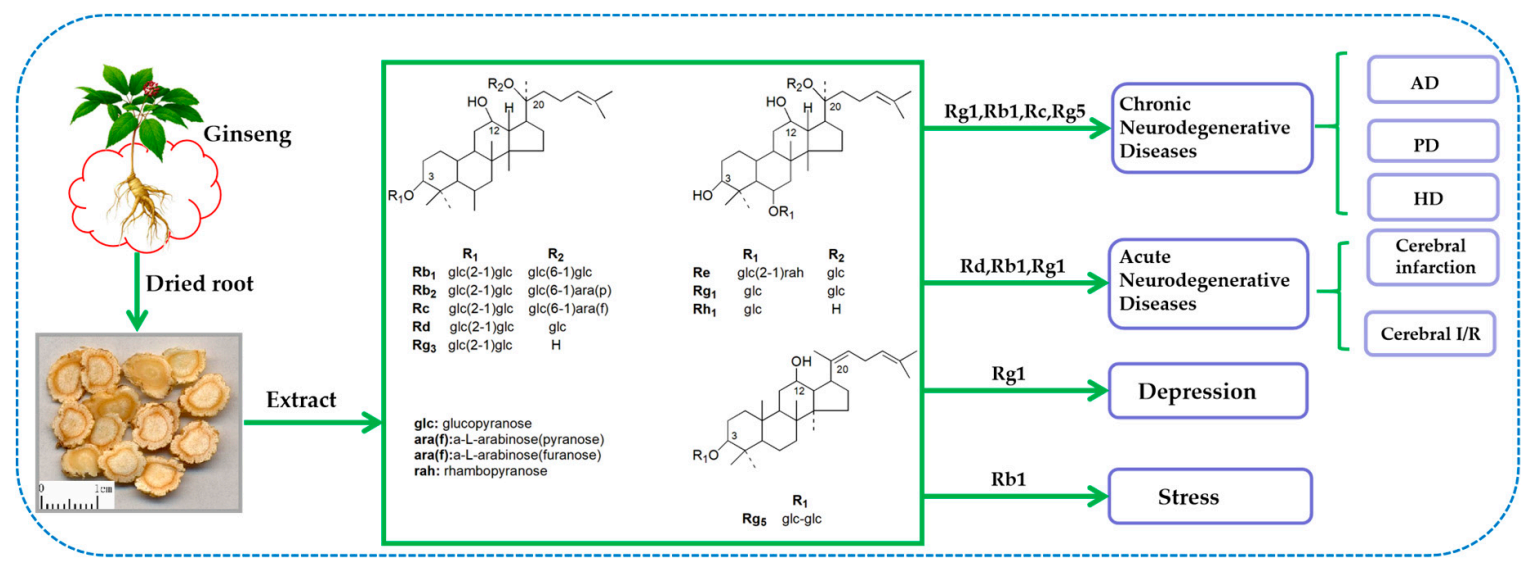

Figure 2. The review's profiling for neuroprotective effects of ginseng phytochemicals.

\section{Chronic Neurodegenerative Diseases}

Chronic neurodegenerative diseases are relatively common and difficult to treat, including AD, PD, and HD [39,40]. Neurodegeneration is a gradual loss of neuronal structure and function [40,41], including neuronal death and glial cell balance, leading to cognitive impairments such as dementia. Among other causes, age (AD, PD) and genetic mutations (HD, early-onset AD or PD, etc.) that affect the function of CNS cells cause chronic neurodegenerative diseases.

Degenerative diseases in the CNS have exhibited an increased incidence rate and have gradually occurred in young people. A large number of in vivo and in vitro experiment research results have 
shown that ginseng has significant neuroprotective activity. Neuroprotection can be defined as a therapeutic intervention (that is, to prevent neuronal death) to reduce disease progression and to delay overprogression from preclinical to clinical by delaying or blocking the neurodegenerative process or delaying the purpose of neuronal death [42]. At present, the neuroprotective effect of ginseng has been increasingly recognized and investigated. The following is a summary of evidence for the role of ginsenosides in some degenerative diseases and their clinical significance.

\subsection{Alzheimer's Disease}

As the most common type of dementia, AD is known as a neurodegenerative disease caused by the degenerative disorders of the CNS [1]. Epidemiological studies have shown that AD mainly occurs in the elderly over 65 years old, after which its incidence increases with age [43]. The main pathological feature of $\mathrm{AD}$ is extracellular $\beta$-amyloid $(\mathrm{A} \beta)$ plaques and intracellular neurofibrillary tangles in the brain. There are also neuronal and white matter losses and inflammatory responses in the relevant brain regions. A significant disability associated with AD is cognitive impairment [44], which interferes with work, activities, relationships, and leisure in daily life. The incidence of AD has increased and has become a substantial economic burden on patients' families and society due to the large aging population. Although $\mathrm{AD}$ is a relatively common and age-related severe disease, its etiology and exact pathogenesis remain unclear, and few treatments are available to reduce or prevent brain cell deterioration [45]. Therefore, it is essential to develop potential therapeutic drugs to avoid or delay AD-related memory decline and to study their effects on the brain of AD patients [46]. These processes, in which multiple etiological and pathological factors work together to modulate the ultimate pathophysiology of the disease, are essential in $\operatorname{AD}[47,48]$. Ginsenosides are the main pharmacologically active ingredients in ginseng: they have been reported to have various effects on the CNS and have become more and more popular as a means of improving cognitive ability in recent years [49].

$\operatorname{Rg} 1$ is a representative monomer in ginseng. Modern pharmacological studies have shown that Rg1 can act on the nervous system in the treatment of elderly AD. However, $\operatorname{Rg} 1$ is easily degraded by the intestinal bacteria after oral administration: the bioavailability is only $1 \%$ to $20 \%$ and is quickly eliminated in the blood [50]. Therefore, the parenteral route might be a potential alternative. The well-characterized transgenic AD mice over expressing amyloid precursor protein/A $\beta$ and nontransgenic littermates at age of six and nine months were treated with $\mathrm{Rg} 1$ for three months via intraperitoneal injection (i.p.) [51]. They assessed changes in amyloidosis, neuropathology, and behavior in mice. The results found that $\operatorname{Rg} 1$ had significant and multifaced neuroprotective effects in their AD mouse model. They noted that Rg1 improved amyloid pathology, modulated the amyloid precursor protein process, improved cognition, and activated hippocampal-dependent protein kinase/hippocampal-respond element-binding protein (PKA/CREB) signaling to induce neuroprotection. These findings show the potential of Rg1 for new classes of drugs for AD treatment and provide new ideas for its treatment.

Chen et al. [52] found that compared to oral Rg1 physiological saline solution, a nasal administration route increased Rg1 distribution and transport efficiency by 5.05 times and 2.50 times, respectively, and shortened the time to $100 \%$ transport in the brain (nasal spray compared to $\operatorname{Rg} 1$ saline in the nasal cavity). The agent increased Rg1 distribution and transport efficiency by 11.80 times and 3.35 times, respectively, and the area under the curve in the brain increased. Therefore, for the application of Rg1 for the prevention and treatment of neurodegenerative diseases, nasal administration is a good route of administration, and nasal spray is an excellent dosage form.

However, the manner of nasal administration is highly irritating, and the patient's compliance is low. On this basis, no obvious irritating transdermal preparation is the right choice. He et al. [53] used a Franz diffusion pool and HPLC on Rg1 in an in vitro transdermal study, and the results showed that Rg1 could penetrate rat abdominal skin without any penetration agent. Lu Jia et al. [54] evaluated the permeability of $\operatorname{Rg} 1$ by studying the transdermal absorption of $\operatorname{Rg} 1$ in injured sites in vitro. The results showed that $\mathrm{Rg} 1$ could penetrate rat abdominal skin and that the steady-state permeation rate $J=0.161 \mathrm{mg} \cdot \mathrm{cm}^{-2} \cdot \mathrm{h}^{-1}$ 
with a time lag of $0.368 \mathrm{~h}$. Sun Yuan et al. [55] investigated the transdermal permeation of Rg1 in cataplasm. The permeation rate $J=40.63 \mu \mathrm{g} \cdot \mathrm{cm}^{-2} \cdot \mathrm{h}^{-1}$ was determined by high performance liquid chromatograph, and the cumulative permeation amount at $24 \mathrm{~h}$ was $173.075 \mathrm{mg} \cdot \mathrm{cm}^{-2}$. They showed that Rg1 had skin permeability, which can prolong medication time, reduce the number of times, and improve the patient's medication compliance when prepared in a transdermal absorbent dosage form.

$\mathrm{Rb} 1$ is a kind of ethanol-soluble compound from ginseng with a high abundance in total ginsenosides, with an excellent safety record. Studies have shown that Rb1 achieves neuroprotection by combating various neurotoxins. A recent study used $A \beta$ amyloid damage primary cultured hippocampal neurons to establish an AD cell model to explore the protective effect and mechanism of ginsenoside Rb1 on hippocampal neurons induced by $\mathrm{A} \beta$ amyloid it was found that $\mathrm{Rb} 1$ showed neuroprotective effects in three ways, namely (1) promoting neural growth, (2) promoting the expression of growth-promoting kinases and helping to prevent their levels from decreasing, and (3) playing the role of an antiapoptotic agent after $A \beta$-induced apoptosis [56].

$\mathrm{Rb} 1$ has been shown to protect the brain from the toxicity caused by aluminum. Zhao et al. [57] treated mice with drinking water containing $\mathrm{AlCl}_{3}$ (200 mg.kg-1 bodyweight) for six months, followed by a post-treatment of $\mathrm{Rb} 1$ oral administration $\left(20 \mathrm{mg} \cdot \mathrm{kg}^{-1}\right.$ per day) for the next four months. They found that treatment with $\mathrm{Rb} 1$ obviously improved memory and learning and reduced tau phosphorylation by reversing the glycogen synthase kinase $3 \beta$ and the protein phosphatase level. The results indicated that $\mathrm{Rb} 1$ protected mice from Al-induced toxicity. The mechanism of action may be to prevent tau hyperphosphorylation by modulating glycogen synthase kinase $3 \beta$ and protein phosphatase levels, suggesting that $\mathrm{Rb} 1$ is a potential prophylactic drug for AD and other neurodegenerative diseases associated with tau pathology.

\subsection{Parkinson's Disease}

PD is also one of the most common types of neurodegenerative disease, ranking only after $\mathrm{AD}$ [58]. The main pathological change in PD is the chronic degeneration of dopaminergic neurons in the substantia nigra pars compacta $(\mathrm{SNpc})$, resulting in decreased dopamine content in the striatum (caudate and putamen) [59,60]. The main symptoms of PD are dyskinesia, including tremors, stiffness, movement retardation, sleep disorders, cognitive impairment, autonomic dysfunction, and depression [61]. These symptoms lead to degenerative changes in the dopaminergic pathway of the SN and striatum. The current treatment methods are mainly divided into two types: one is a symptomatic treatment for motor symptoms, and the other modifies potential diseases by protecting or restoring neurons. However, the current pharmacological treatment for PD remains at the symptomatic treatment stage, there has been no further development, and this symptomatic treatment has no way to lose dopaminergic neurons in PD patients progressively. Thus, it is vital to have an in-depth understanding of the molecular mechanism of PD and to discover new PD therapeutic agents with high efficiency [62].

The protective effect of ginsenoside extracted from ginseng on the toxicity of $\alpha$-synuclein has been evaluated. Of all the ginsenosides (i.e., Rb1, Rg3, and Rg1) screened, only Rb1 was shown to be a potent inhibitor of alpha-synuclein fibrillation and toxicity, thereby acting as a defibrillation. Therefore, Rb1 can be used as a drug for treating PD and related diseases [63]. When exposed to a toxic compound (methyl-polypyridine-iodide) mouse dopaminergic cells began to die, and neurite length was shortened. In addition, the level of immune-positive tyrosine hydroxylase cells decreased. Rb1 and Rg1 were administered to counteract this process. Although these compounds could not prevent cell loss, they prevented neuronal degeneration by increasing the length of neurites in surviving neurons, thereby suggesting their partial neuroprotective effect [64].

Ginsenoside Rg1 is a vital chemical component of ginseng, with low toxicity, neuroprotective, and anti-inflammatory effects. A recent study investigated the potential of $\operatorname{Rg} 1$ to treat PD and used in vivo and in vitro models of PD to investigate whether Rg1 exerts neuroprotection through the Wnt/ $\beta$-catenin signaling pathway. In an in vivo study of this experiment, dopaminergic cell loss induced by 1-methyl-4-phenyl-1,2,3,6-tetrahydropyridine (MPTP) in a dose-dependent manner was 
reduced after models of PD rats were administered an i.p. injection of $\operatorname{Rg} 1$ for 15 consecutive days. In vitro, after pretreatment with Rg1, cell viability was enhanced, and 1-methyl-4-phenylpyridinium $(\mathrm{MPP}+)$-induced cell apoptosis was reduced. The results demonstrated that Rg1 shows neuroprotective effects not only in in vivo but also in in vitro PD models, and these effects act through the $\mathrm{Wnt} / \beta$-catenin signaling pathway [62]. Another study found that MPTP-induced animal survival rates, the loss of dopamine neurons, motor deficits, and abnormal ultrastructural changes in the SNpc were significantly improved by oral $\operatorname{Rg} 1$ administration. In addition, they also found that the anti-neuroinflammatory properties of Rg1 may be involved in neuroprotection. In their experiments, Rg1 was found to exhibit neuroprotective effects in a chronic MPTP/propionate-induced PD mouse model. Increased blood brain barrier (BBB) permeability caused by inflammation in the CNS may lead to immune cells and peripheral toxins entering the brain and thus causing degeneration, which is characteristic of PD. In the SNpc and striatum of MPTP-treated mice, an infiltration of CD4+ and CD8+ T lymphocytes could be found [65].

Zhou et al. [66] confirmed that i.p. administration of $\operatorname{Rg} 1$ for 15 consecutive days could protect anti-tyrosine hydroxylase positive cells in the SNpc region from MPTP toxicity measured with immunofluorescence and found that CD3+ T cells accumulated in the SNpc and that Rg1 treatment reduced the infiltration of $\mathrm{T}$ cells in this region. They demonstrated the immunoprotection of $\mathrm{Rg} 1 \mathrm{in}$ an MPTP-induced PD mouse model and provided a new therapeutic approach for the treatment of PD from an immunological perspective. Table 1 summarizes the basic and clinical evidence for the beneficial effects of ginseng on AD and PD in a more intuitive way. 
Table 1. Summary of the treatment of ginsenosides in Parkinson's disease (PD) and Alzheimer's disease (AD).

\begin{tabular}{|c|c|c|c|c|c|}
\hline Ginsenoside & Activities & Models & Dosing and Administration & Mode of Action & Ref. \\
\hline $\begin{array}{l}\text { 20(S)-proto-panaxadiol } \\
\text { nanocrystals }\end{array}$ & $\begin{array}{l}\text { Neurodegenerative } \\
\text { disease }\end{array}$ & $\begin{array}{l}\text { A polyethylene catheter was cannulated into } \\
\text { the right jugular vein of the rats } \\
\text { under anesthesia }\end{array}$ & $\begin{array}{l}20 \mathrm{mg} / \mathrm{kg} \\
\text { Oral }\end{array}$ & $\begin{array}{l}\text { Increased plasma Cmax and } \\
\text { increased bioavailability }\end{array}$ & [67] \\
\hline $\begin{array}{l}\text { Korean red ginseng } \\
\text { extract }\end{array}$ & PD & $\begin{array}{l}\text { The rats were administered } \\
\text { 1-methyl-4-phenyl-1,2,3,6-tetrahydropyridine } \\
\text { (MPTP)-HCl by i.p. }\end{array}$ & $\begin{array}{l}100 \mathrm{mg} / \mathrm{kg} \\
\text { Oral }\end{array}$ & $\begin{array}{l}\text { Restored MPTP-induced } \\
\text { protein downregulation }\end{array}$ & [61] \\
\hline $\operatorname{Rg} 1$ & PD & $\begin{array}{l}\text { The rats were administered MPTP- } \mathrm{HCl} \text { by } \\
\text { i.p. }\end{array}$ & $\begin{array}{l}5 \mathrm{mg} / \mathrm{kg}, 10 \mathrm{mg} / \mathrm{kg} \text {, and } 20 \mathrm{mg} / \mathrm{kg} \\
\text { i.p. }\end{array}$ & $\begin{array}{l}\text { Decreased MPP+-induced cytotoxicity } \\
\text { Protected PC12 cells from MPP+-induced } \\
\text { apoptosis. }\end{array}$ & [62] \\
\hline $\operatorname{Rg} 1$ & PD & The chronic MPTP/probenecid model & $\begin{array}{l}10 \mathrm{mg} / \mathrm{kg}, 20 \mathrm{mg} / \mathrm{kg} \text {, or } 40 \mathrm{mg} / \mathrm{kg} \\
\text { Oral }\end{array}$ & $\begin{array}{l}\text { Improved high MPTP-induced behavior defects, } \\
\text { loss of dopamine neurons, mortality, and } \\
\text { abnormal ultrastructure changes in the SNpc }\end{array}$ & [65] \\
\hline $\operatorname{Rg} 1$ & PD & $\begin{array}{l}\text { Two weeks after ovariectomy, unilateral } \\
\text { infusion of lipopolysaccharide into the right } \\
\text { side of substantia nigra pars compacta } \\
\text { (SNpc) under anesthesia }\end{array}$ & $\begin{array}{l}\mathrm{Rg} 110 \mathrm{mg} / \mathrm{kg}, 10 \mathrm{mg} / \mathrm{mL} \\
\text { i.p. }\end{array}$ & $\begin{array}{l}\text { Showed protective effects on mesencephalic } \\
\text { dopaminergic neurons }\end{array}$ & {$[68]$} \\
\hline Panax ginseng extract & PD & $\begin{array}{l}\text { Injected a solution of rotenone in the right } \\
\text { striatum of rat bregma }\end{array}$ & $\begin{array}{l}100 \mathrm{mg} / \mathrm{kg} \\
\text { Oral }\end{array}$ & $\begin{array}{l}\text { Improved the midbrain and striatal changes and } \\
\text { showed a partial ameliorative effect against a rat } \\
\text { model of PD }\end{array}$ & [69] \\
\hline $\mathrm{Rb} 1$ & $\mathrm{AD}$ & $\begin{array}{l}\text { SH-SY5Y cells used stable isotope labeling } \\
\text { with amino acids in cell culture }\end{array}$ & $\begin{array}{l}100 \mathrm{mM} / \text { day } \\
\mathrm{Rb} 1 \text { pretreatment }\end{array}$ & $\begin{array}{l}\text { Prevented } \beta \text {-amyloid-induced neurotoxicity in } \\
\text { SH-SY5Y cells and apoptotic cells; increased the } \\
\text { expression of actin cytoskeleton proteins }\end{array}$ & [70-72] \\
\hline Ginseng total saponins & $\mathrm{AD}$ & $\begin{array}{l}\text { SAM, senescence-accelerated mouse; SAMP, } \\
\text { senescence-accelerated mouse prone } \\
\text { substrain; SAMR, senescence-accelerated } \\
\text { mouse-resistant substrain }\end{array}$ & $\begin{array}{l}50,100 \text {, and } 200 \mathrm{mg} / \mathrm{kg} / \text { day } \\
\text { Oral }\end{array}$ & $\begin{array}{l}\text { Prevented memory loss in aged SAMP8 mice by } \\
\text { upregulating the increase in antioxidant capacity } \\
\text { in the hippocampus and upregulating } \\
\text { plasticity-related proteins }\end{array}$ & [73] \\
\hline
\end{tabular}




\subsection{Huntington's Disease}

HD is an autosomal-dominant, inherited, progressive neurodegenerative disorder caused by the repeated expansion of cytosine-adenine-guanine in the Huntington gene on chromosome 4 [74], in which the patients exhibit numerous symptoms, including cognitive, motor, and behavioral impairments, in which clinical heterogeneity during the disease is common [75-77]. This dysfunction contributes to the expression of the clinical symptoms of HD. Up to now, there has been no drug treatment available on the market to improve or prevent HD effectively. Since there are no available treatments to assess progressive neuronal dysfunction, behavioral and psychiatric symptoms can only be managed through the use of conventional therapies.

Considerable efforts have been recently devoted to the use of herb and botanical-derived products to prevent and treat HD. To evaluate the neuroprotective activity of ginsenosides, Wu et al. [78] investigated the effect of 10 different ginsenosides on HD by using an in vitro model of the mouse medium-sized multispinous striatum nerve YAC128. Ginsenosides exhibited a protective effect on $200 \mu \mathrm{M}$ glutamate-induced apoptosis after pretreatment with saponins Rb1, Rc, and Rg5. However, the seven other samples of ginsenosides (Re, Rd, Rg3, Re, Rh1, Rd, a combination of Rg5 and Rk1, and a mixture of Rk3 and Rh4) had no protective effect on the glutamate-induced apoptosis of multispinous striatum nerve YAC128 cells. At a concentration of $1 \mu \mathrm{M}, \mathrm{Re}, \mathrm{Rh} 1$, and a mixture of Rk1 and Rg5 exhibited toxicity. Subsequent studies have shown that the neuroprotective effects of $\mathrm{Rb} 1, \mathrm{Rc}$, and $\operatorname{Rg} 5$ are associated with an inhibition of glutamate-induced changes in $\mathrm{Ca}^{2+}$ concentrations. These results indicate that $\mathrm{Rb} 1, \mathrm{Rg} 5$, and $\mathrm{Rc}$ may serve as a medicine for the treatment of neurodegenerative diseases, including HD.

The exact cause of neuronal cell death in HD is unknown. Systemic administration of 3-nitropropionic acid (3-NP), which is an irreversible succinate dehydrogenase inhibitor, induces cellular adenosine triphosphate depletion and causes a selective striatal degeneration similar to that observed in HD. A previous study evaluated the in vitro and in vivo effects of ginsenosides on striatal neurotoxicity induced by 3-NP repeat treatment in rats. They dissolved ginsenosides in saline and administered different doses to rats i.p. The results suggested that 3-NP-induced rat striatum degeneration is inhibited by ginsenosides. These compounds were shown to increase the survival rate of HD animals, inhibit intracellular $\mathrm{Ca}^{2+}$ elevation, and reduce behavioral disorders after toxin administration [79].

\section{Acute Neurodegenerative Diseases}

Acute neurodegenerative diseases mainly include cerebrovascular accidents, stroke sequelae, and the like. A stroke is a brain obstruction or rupture in the brain's blood supply caused by disease, with high mortality and high disability, and it is the leading cause of elderly permanent disability and death. The incidence of stroke in developed countries is lower than in developing countries, and stroke is a more serious problem in developing countries [80]. Stroke is mainly divided into two types: one is an ischemic stroke, primarily due to infarction, and the other is a hemorrhagic stroke, mainly due to intracerebral/parenchymal or subarachnoid hemorrhage. These two types of strokes affect the brain in different ways. Ischemic strokes and hemorrhagic strokes account for $85 \%$ and $15 \%$ of strokes, respectively: about 6 million people die each year from stroke, and the lifetime risk of stroke is estimated to be $8 \%$ to $10 \%[81,82]$. Currently, the most effective way to treat cerebral infarction is to restore the blood supply by recanalization of the occluded arteries or by endovascular therapy or thrombolytic agents immediately after arterial occlusion. However, recanalization therapy may make brain damage worse: this is called ischemia-reperfusion injury $(\mathrm{I} / \mathrm{R})$, and it results in poor clinical outcomes because of fatal edema (brain herniation) or intracranial hemorrhage after thrombolysis [83]. Thrombolytic therapy is effective for acute ischemia, but its application is limited by time windows and contraindications. Currently, there is no effective treatment for strokes caused by neuronal damage and death [84]. 


\subsection{Cerebral Infarction}

Ginsenosides have various pharmacological effects and limited clinical efficacy in the treatment of stroke and other cerebrovascular diseases. Among the different neuroprotective drugs currently used, Rd ginsenosides have apparent clinical efficacy on acute cerebral ischemia [85-87]. To date, studies have shown that $\mathrm{Rb} 1$ exhibits neuroprotection in a rodent ischemic model. Some researchers have investigated the effects of $\mathrm{Rb} 1$ on early and delayed brain injuries in a nonhuman primate thromboembolic stroke model [88]. They showed that by injecting autologous blood clots into the left internal carotid artery, occlusion of the middle cerebral artery could induce a thromboembolic stroke. $\mathrm{Rb} 1$ at $300 \mu \mathrm{g} \cdot \mathrm{kg}^{-1}$ per day or saline was administered into the cephalic vein of the forearm for seven days before embolization on the day following embolization. Subsequently, a positive reaction was evaluated by several measurements, and it was shown that $\mathrm{Rb} 1$ did improve early and delayed damage in a thromboembolic stroke model of nonhuman primates.

One of the main causes of brain damage is bleeding, leading to cerebral edema. Recent trials have shown that $\mathrm{Rb} 1$ plays an important role in improving complications following an ischemic brain event. In that study [89], a rat model of subarachnoid hemorrhage was used, and Rb1 was intravenously administration at a dose of $20 \mathrm{mg} \cdot \mathrm{kg}^{-1} 30 \mathrm{~min}$ after the first brain injury caused by subarachnoid bleeding. The same treatment was continued for seven days. Then, brain edema significantly reduced, and neurobehavioral functioning improved. In addition, a histological examination showed a significant reduction in lumen thickness and basilar artery vasospasms with treatment. The experimental results showed that $\mathrm{Rb} 1$ could resist brain damage caused by hemorrhage.

To assess the therapeutic and preventive effects of $\mathrm{Rb} 1$ on a neural injury during cerebral infarction, Jiang et al. used a model of middle cerebral artery occlusion (MCAO) in rats to study the effects of $\mathrm{Rb} 1$ with edaravone (a neuroprotective agent) as a control. Rb1 was intragastrically administered to the rats either before or after MCAO surgery to determine its therapeutic and preventive effects. The infarct volume of rats treated with $\mathrm{Rb} 1$ was less than that of edaravone, which suggests the potential of ginsenosides as a neuroprotectant [90]. Studies have shown that ginsenosides promote ischemia and brain damage after the proliferation and differentiation effects of neural stem cells (NSCs). Hypoxia-inducible factor- $1 \alpha$ (HIF- $1 \alpha)$ is a transcription factor in hypoxia for the proliferation of and differentiation of NSCs that plays an important regulatory role of vascular endothelial growth factor and HIF- $1 \alpha$ in hypoxia in the expression of cytokines are closely related to nerves and blood vessels. In a microenvironment under the condition of cerebral ischemia and hypoxia, ginsenosides regulated the proliferation and differentiation of NSCs through the HIF- $1 \alpha$-vascular endothelial growth factor (VEGF) pathway. Ginsenosides acting on the expression of HIF-1 $\alpha$ in the nest were controlled by the expression of HIF- $1 \alpha$, and the expression of VEGF in the downstream target gene was promoted. The paracrine mode helped the cascade of microvascular proliferation and neurogenesis, regulated NSCs, and promoted the proliferation and differentiation of NSCs. It lays the foundation for the transplantation of NSCs and treatment of stroke and other brain damage to the CNS diseases.

Studies have shown that ginsenosides can promote coculture conditions in the proliferation of NSCs and induce NSCs to differentiate neurons and glial cells in the case of cerebral ischemia and hypoxia. This mechanism may be related to the control of ginsenosides in the HIF- $1 \alpha-$ VEGF pathway. Ginsenosides can act on the astrocytes in the nest. Brain injury repair and brain function restoration can be achieved by regulating the transcription of the HIF- $1 \alpha$ gene, promoting the activation of HIF- $1 \alpha$, initiating the expression of VEGF downstream of the target gene, acting in a paracrine manner in NSCs, improving the microenvironment of NSCs, promoting the proliferation and, differentiation of NSCs to play a neuroprotective effect [91]. Zheng et al. [84] conducted an experiment on male Wistar rats. Three days before the establishment of the permanent MCAO model, the rats were intraperitoneally injected with $25-\mathrm{mg} \cdot \mathrm{kg}^{-1} \cdot \mathrm{d}^{-1}$ doses of total ginsenoside or the same volume of normal saline. The same treatment was continued until the animals were killed on the 1st, 3rd, 7th, and 14th day. Neurological function was blindly assessed. The results demonstrated that ginseng total saponins could improve neurological function deficits after focal cerebral ischemia by enhancing adult CNS regeneration and 
inducing the endogenous activation of NSCs. In a previous study, participants were selected using a replacement zonal randomization method based on the National Institutes of Health Stroke Scale score and randomized into two treatment groups. Patients simultaneously received a placebo or ginsenosides at a dose of $1 \mathrm{mg} \cdot \mathrm{kg}^{-1}$ per body (maximum $100 \mathrm{mg}$ ) with $10 \%$ recombinant tissue plasminogen activator as a bolus followed by the remaining $90 \%$ as a constant infusion for $60 \mathrm{~min}$. This supported the clinical use of ginsenosides as a potential supplement with recombinant tissue plasminogen activator treatment, which can reduce symptomatic intracerebral hemorrhage and improve the treatment outcome of stroke patients [92].

\subsection{Cerebral Ischemia-Reperfusion Injury}

Cerebral ischemia-reperfusion injury (I/R) is a complex pathophysiological event that is associated with hypoxia and the energy depletion of brain tissue during ischemia, ultimately leading to neuronal destruction. High recurrence rates, high mortality, and high disability are the resulting characteristics of the damage and cascade reactions caused by cerebral ischemia. However, so far, only a few antithrombotic drugs, such as heparin, recombinant tissue plasminogen activator, and aspirin [93], can be used for the treatment of ischemic stroke, and the safety issues associated with reperfusion injury and hemorrhage are uncontrollable. Therefore, several potential neuroprotective agents should be investigated for the treatment of cerebral ischemia and reperfusion injury to reduce safety concerns caused by antithrombotic drugs in ischemic stroke.

The four compounds Rb1, Rg1, schizandra, and DT-13 ((25(R,S)-ruscogenin-1-O-[ $\beta$-D-glucopyranosyl-( $1 \rightarrow 2)][\beta$-D-xylopyranosyl-( $1 \rightarrow 3)]$ - $\beta$-D-fucopyra-noside) $)$ combined in a specific ratio $(6: 9: 5: 4$ $w / w$, called SMXZF) showed neuroprotective activity. In the experiments of Guo et al. [94], male C57BL/6 mice were subjected to I/R injury using right MCAO for $1 \mathrm{~h}$ with subsequent $24-\mathrm{h}$ reperfusion. Three doses of SMXZF $\left(4.5,9\right.$, and $\left.18 \mathrm{mg} \cdot \mathrm{kg}^{-1}\right)$ were i.p. administered after ischemia for $1 \mathrm{~h}$. An autophagic inhibitor, 3-methyladenine $\left(300 \mu \mathrm{g} \cdot \mathrm{kg}^{-1}\right)$, was i.p. administered $20 \mathrm{~min}$ before ischemia as a positive drug. The results demonstrated that SMXZF showed neuroprotection through three pathways. First, SMXZF inhibited autophagy via a reduction in autophagosomes. Second, SMXZF increased cerebral blood flow and counteracted infarction. Finally, SMXZF significantly inhibited the phosphorylation of adenosine monophosphate-activated protein kinase and the mammalian target of rapamycin and the expression of c-Jun N-terminal kinase and its phosphorylation induced by 24-h reperfusion. Their study revealed that SMXZF displayed neuroprotective effects against focal I/R. In another study, cerebral ischemia was evaluated by a 2-h occlusion of the middle cerebral artery and reperfusion followed by i.p. administration of $\mathrm{Rb} 1\left(40 \mathrm{mg} \cdot \mathrm{kg}^{-1}\right)$ and saline. The result demonstrated that $\mathrm{Rb} 1$ promoted neural behavior recovery, increased brain-derived neurotrophic factor expression, decreased caspase-3 (an essential component of an apoptotic pathway) activity, and induced neurogenesis after cerebral ischemia. These results provided new evidence for the protection of neurons by Rb1from reperfusion injury [95].

Rg1 has been proven to possess protective effects over the CNS. In a study by Wang Rui et al. [96], rats were administered with $\operatorname{Rg} 1\left(45 \mathrm{mg} \cdot \mathrm{kg}^{-1}\right)$ by intravenous injection (i.v.) $1 \mathrm{~h}$ before focal ischemia and $3 \mathrm{~h}$ after reperfusion. The results showed that $\mathrm{Rg} 1$ exhibited a potent neuroprotective effect by significantly reducing neurological scores and the brain infarct volume in MCAO rat models. The active ingredient of ginseng, Rg1, was shown to scavenge free radicals and improve antioxidant capacity. The pathogenesis of neurons injured by cerebral ischemia is complicated and is associated with oxygen-free radical injury, inflammatory factor damage, excitatory amino acid injury, and intracellular $\mathrm{Ca}^{2+}$ overload [97]. Among these injuries, oxidative stress-induced oxygen-free extreme trauma has attracted considerable attention [98]. Brain tissues contain abundant unsaturated fatty acids and are susceptible to damage by free radicals [99]. The results of Sun et al. [100] indicated that $\mathrm{Rg} 1 \mathrm{resisted}$ oxidative stress and free radical injury, increased the survival rate of damaged cells, reduced the amount of leaked lactate dehydrogenase and caspase- 3 activation, increased superoxide dismutase 
(SOD) activity and heat shock protein 70 expression, and suppressed cell apoptosis in a dose-dependent manner. Table 2 lists some basic and clinical evidence for the beneficial effects of ginseng on I/R.

Table 2. The ginsenoside experimental method for treating I/R.

\begin{tabular}{|c|c|c|c|c|}
\hline Ginsenoside & Models & Dosing/Administration & Mode of Action & Ref. \\
\hline $\mathrm{Rd}$ & $\begin{array}{l}\text { Induced by } \\
\text { transient } \\
\text { MCAO }\end{array}$ & $\begin{array}{l}50 \mathrm{mg} \cdot \mathrm{kg}^{-1} \\
\text { i.p. }\end{array}$ & $\begin{array}{l}\text { Improved behavior score, viability, and infarct } \\
\text { volume of the cultured neurons after ischemia } \\
\text { and protected Sprague Dawley rats and cultured } \\
\text { neurons from I/R. }\end{array}$ & [101] \\
\hline $\begin{array}{l}\text { Ginseng total } \\
\text { saponins }\end{array}$ & $\begin{array}{l}\text { Induced by } \\
\text { transient } \\
\text { MCAO }\end{array}$ & $\begin{array}{l}25 \mathrm{mg} \cdot \mathrm{kg}^{-1} \cdot \mathrm{d}^{-1} \\
\text { i.p. }\end{array}$ & $\begin{array}{l}\text { Improved the regeneration of the central nervous } \\
\text { system in adults, thereby improving neurological } \\
\text { deficits after focal cerebral ischemia. }\end{array}$ & [84] \\
\hline $\operatorname{Rg} 1$ & $\begin{array}{l}\text { Induced by } \\
\text { transient } \\
\text { MCAO }\end{array}$ & $\begin{array}{l}45 \mathrm{mg} \cdot \mathrm{kg}^{-1} \\
\text { i.v. }\end{array}$ & $\begin{array}{l}\text { Showed effective neuroprotection by reducing } \\
\text { the brain infarct volume and neurological scores. }\end{array}$ & [96] \\
\hline Rg1 & $\begin{array}{l}\text { Induced by } \\
\text { transient } \\
\text { MCAO }\end{array}$ & $\begin{array}{l}40 \mathrm{mg} \cdot \mathrm{kg}^{-1} \cdot \mathrm{d}^{-1} \\
\text { i.p. }\end{array}$ & $\begin{array}{l}\text { Showed it was neuroprotective by improving } \\
\text { neurological damage, BBB permeability, and the } \\
\text { brain infarct volume. }\end{array}$ & [102] \\
\hline
\end{tabular}

These previous studies have shown that $\operatorname{Rg} 1$ exerts significant neuroprotective effects and is neurotrophic in hypoxic ischemic insults in vivo and in vitro [103]. On the basis of these studies, several researchers have built a focal cerebral ischemia model that is induced by MCAO. The researchers conducted i.p. administration of $\operatorname{Rg} 1$ on rats at a dose of $40 \mathrm{mg} \cdot \mathrm{kg}^{-1} \cdot \mathrm{d}$. They used Longa's five-point scale to perform neurological examinations, the brain infarct volume was determined by 2, 3, 5-triphenyltetrazolium chloride staining, and the permeability of the BBB was evaluated by Evans blue dye. Western blot and quantitative reverse transcription-polymerase chain reaction were used to assess protease-activated receptor- 1 expression. The results indicated that $\operatorname{Rg} 1$ alleviates neurological dysfunction and reduces the BBB permeability in I/R rats. The mechanisms by which Rg1 prevents focal cerebral ischemia includes the regulation of protease-activated receptor-1 expression [102].

$\mathrm{Rd}$ is another active ingredient in ginseng. Much clinical research has proven that the treatment of acute ischemic stroke with $\mathrm{Rd}$ is effective and safe [11]. Considerable studies have shown that $\mathrm{Rd}$ protects neurons from $\mathrm{I} / \mathrm{R}$ by decreasing redox injury, inhibiting apoptosis, and maintaining mitochondrial function [103-106]. Ye et al. [107] used Rd with concentrations ranging from $0.1 \mathrm{mg} \cdot \mathrm{kg}^{-1}$ to $200 \mathrm{mg} \cdot \mathrm{kg}^{-1}$ or vehicle applied i.p. $30 \mathrm{~min}$ before MCAO and found that when the dose of Rd was $10-50 \mathrm{mg} \cdot \mathrm{kg}^{-1}$, the infarct volume was significantly reduced and improved long-term neurological outcomes up to six weeks after ischemia. This results demonstrated the neuroprotection of Rd in transient focal ischemia, which may involve an integrated process of scavenging pathways of early free radicals and a late anti-inflammatory effect. Ye et al. [108] evaluated the protective role of Rd in attenuating ischemic neuronal injury through cell experiments. In addition, Rd stabilized the mitochondrial membrane potential and attenuated the apoptotic death of hippocampal neurons after oxygen-glucose deprivation exposure. From these findings, it can be seen that Rd has potential as a neuroprotective agent for cerebral ischemic injury, and further research is meaningful and worthy of encouragement. Rd reduced the BBB permeability and alleviated the neurological dysfunction in $\mathrm{I} / \mathrm{R}$ rats. The mechanisms by which Rd prevents focal cerebral ischemia include the regulation of protease-activated receptor-1 expression [102]. Xie et al. [101] administered $\mathrm{Rd}$ (50 mg/kg) or an equal volume of saline containing 10\% 1,3-propanediol (v/v) by i.p. $30 \mathrm{~min}$ before MCAO surgery or immediately after an MCAO operation. The results showed that in a MCAO rat model and a neuron model of oxygen-glucose deprivation culture, Rd significantly improved the infarct volume, behavioral score, and viability of cultured neurons after I/R. Rd decreased the overexpression of the $\mathrm{N}$-methyl-D-aspartate receptor 2B subunit in the membrane and its hyperphosphorylation after I/R. Rd protected Sprague Dawley rats and cultured neurons from I/R by inhibiting the overexpression of 
the $\mathrm{N}$-methyl-D-aspartate receptor 2B subunit in the membrane and its hyperphosphorylation. This indicates that $\mathrm{Rd}$ is a potentially useful drug for preventing or treating $\mathrm{I} / \mathrm{R}$.

\section{Depression}

Depression, which has become a prevalent psychiatric disorder, has been shown to be associated with notable changes in specific brain regions [109]. The main symptoms of depression are depression, lack of pleasure and mental retardation. It is a chronic, recurrent episode of emotional psychosis, and patients have a serious suicidal tendency. The prevalence of depression has increased annually because people face various pressures, and the pathogenesis of the study has attracted considerable attention [110]. The pathogenesis of depression is unclear because the medical community mainly uses two categories, namely monoamine neurotransmitter theory and non-monoamine neurotransmitter pathogenesis (which includes non-monoamine neurotransmitters, a focus of study in recent years). At present, treatments for depression are mainly western medicine treatments, psychological treatments, and hospital care therapy. A large number of clinical applications and experimental studies have found that traditional Chinese medicine, especially ginseng, plays a role in antidepression, and its antidepressant effects have attracted the attention of many researchers.

Gap junctional dysfunction between astrocytes in the prefrontal cortex is associated with major depressive disorder. In one study, rats were exposed to chronic unpredictable stress and were administered $\operatorname{Rg} 1\left(5,10\right.$, and $\left.20 \mathrm{mg} \cdot \mathrm{kg}^{-1}\right)$ for 28 days intragastrically, and a forced swimming test and sucrose preference were used to analyze depressive symptoms in rats [111]. Their findings demonstrated that $\operatorname{Rg} 1$ remarkably alleviated depression-like behavior in rats. This research provided a new perspective on the use of $\operatorname{Rg} 1$ as an antidepressant and opened up the possibility of studying the natural bioactive substances used in traditional Chinese medicines, which may have high efficiency and few side effects, to treat depression.

Some studies have found that oral ginseng extract causes a therapeutic effect on women with menopausal depression. Jeong et al. [112] randomly selected 35 women aged 18-65 years from outpatients, administered red ginseng, and used the Montgomery-Asberg Depression Scale and Depression Symptom Scale to assess depressive symptoms. The severity of depression significantly improved, which indicated that Korean red ginseng as an adjuvant therapy could effectively change the residual symptoms of patients with depression. Subsequently, Lee et al. [113] expanded the clinical sample size by randomly dividing 93 postmenopausal women into two groups: the first group was administered a placebo, and the second group was administered ginseng capsules. After two weeks, a blood test and a depression scale questionnaire were given to the two groups. Depressive symptoms were relieved in patients with depression in the ginseng group.

\section{Stress}

Stress can decrease the levels of a brain-derived neurotrophic factor (BDNF) and make change in heat shock protein-70 which are valuable as anti-stress agents to induce dysfunction in the brain part known as hippocampus. Rb1 administration increases the levels of heat shock protein-70 and BDNF, eliminates the effects of stress, and avoids any damage to the hippocampus [114]. Ginsenosides have been recognized as neuroprotective agents, including playing a role as antistress ingredients. The main active compounds of ginseng, including the ginsenosides $\mathrm{Rb} 1$ and $\mathrm{Rg} 3$, were administered to stress gerbil mice, and the levels of stress marker polyamines, especially putrescine levels, were evaluated. In the experimental results, $\mathrm{Rb} 1$ and $\mathrm{Rg} 3$ obviously reduced the levels of stress markers, acted against stress, and established themselves as stress control elements [115,116].

Mice exposed to stress were treated with $\mathrm{Rb} 1$ and assessed for stress-induced levels of brain monoamine. The results indicated that $\mathrm{Rb} 1$ reversed stress-induced changes in brain monoamine levels, and $\mathrm{Rb} 1$ was an antistress factor [117]. Tyrosine kinase B (TrkB), whose concentrations may play an essential role in neurosurvival and differentiation, is an important member of the kinase family and is a neurotrophic factor. Immobilized stressed rats were treated with Rb1, and it was 
found that Rb1 increased TrkB levels by upregulating mRNA. At the same time, stress-relieving levels of adrenocorticotropic hormone and corticosterone (CORT) increased. Therefore, Rb1 actively resisted immobilization stress [118]. Ginsenosides have been demonstrated to be antistress agents in previous studies. In one study, ginsenosides were found to be associated with learning ability and sleep deprivation stress. Sprague Dawley rats were exposed to sleep pressure to affect their learning ability and were then subjected to $\mathrm{Rb} 1$ treatment. Later experiments showed that $\mathrm{Rb} 1$ obviously increased the level of somatostatin, which is a neuromodulator. Furthermore, learning and memory skills improved [119]. A number of studies have focused on assessing the role of $\mathrm{Rb} 1$ as a neuroprotective agent by improving mitochondrial stability. After Rb1 treatment, SH-SY5Y cells were subjected to glucose and oxygen stress. $\mathrm{Rb} 1$ suppressed toxic oxygen radicals and increased mitochondrial membrane stability to significantly increase cell viability. $\mathrm{Rb} 1$ also promoted $\mathrm{Bcl}-2$, which is a potent antiapoptotic factor, and counteracted increasing levels of proapoptotic Bax. Therefore, Rb1 could increase neuronal cell protection and mitochondrial stability [120].

\section{Conclusions and Future Perspectives}

Over the years, evidence for the medicinal and health benefits of ginseng in the prevention of neurodegenerative diseases has increased, and there are currently no clinically reported severe adverse reactions. Therefore, the unique ability of ginseng to prevent neurodegeneration is increasingly of concern to consumers and researchers. Most experiments on the treatment of neurodegeneration are aimed at determining the effects of drugs on neurons, but neglecting the support and nutrition of neuromuscular fibers in neuronal growth. Tests have shown that ginseng can be used as a drug to affect neurons [121] and to achieve peripheral nerve regeneration to prevent muscle atrophy.

Ginseng and its saponins are useful as drugs for the treatment of brain diseases caused by their neuroprotective effects. At present, there are two main aspects to this. One is the relationship between the prototype of ginsenoside and its activity, and the other is the study of its metabolic profile and the association of metabolites with activity. Research on the transformation of flora in the digestive tract has been relatively detailed, but metabolism research in the body is still difficult. This is the main direction that should be addressed in future research on ginseng and its saponins.

The beneficial effects of ginseng and its biologically active ingredients, ginsenosides, have been reported and have attracted considerable attention from researchers. Most previous studies have been conducted in cellular and animal models and have focused on neurons. Most ginsenosides had lower bioavailability and a less popular distribution in the brain. The transport capacity of ginsenosides through the BBB was relatively limited because they were not detected in the brain tissue of MCAO and normal rats. Although their transport through a BBB-damaged model (in vitro), which was induced by hydrogen peroxide, was slightly enhanced, the results in that study indicated that the permeability of the BBB was poor. The low permeability of the BBB is the primary obstacle to overcome in for the treatment of brain diseases. Although varying degrees of brain disease will be associated with local BBB damage, but the formation of BBB low permeability of the key structure of the existence of close connections still limit the drugs into the brain to achieve effective diagnosis and treatment concentration. Therefore, a highly efficient and safe method should be developed for the treatment of CNS diseases. A study on the delivery of drugs across the BBB has provided new ideas for drug delivery strategies in the brain and guidance for the construction of nanomedicine in the diagnosis and treatment of brain diseases such as PD and AD. At present, the domestic dosage of Chinese patent medicines containing ginsenoside is enormous: some are oral, and there are many traditional Chinese medicine injections, all of which are aimed at this type of disease. Therefore, clinical practice in China is prosperous, but there is a lack of systematic research integration and reassessments of post-marketing efficacy, and especially a lack of senior clinical research. Future researchers should conduct research integration and re-evaluations of post-marketing efficiency, particularly to provide high-level theoretical studies of clinical research and thoroughly elucidate cellular and molecular mechanisms and provide a number of signal transduction pathways to reveal the mystery of ginsenosides. 
In summary, previous studies on ginsenosides have powerfully shown that ginsenosides and their metabolites/derivatives are potential stocks as active agents in the prevention and treatment of brain diseases in the future. In addition, their neuroprotective effects and mechanisms of action are worthy of further research and proof by scholars.

Author Contributions: B.W. and T.Z. contributed to the conception of the review, X.H. contributed significantly to the complete manuscript preparation, and N.L. and Y.P. contributed to constructive discussions. All authors read and approved the review.

Funding: This research was funded by Program of Shanghai Committee of Science and Technology, China, grant number was 17401902300; Program of Shanghai Academic/Technology Research Leader, China, grant number was 18XD1403700; Applied Basic Research Programs of Yunnan Province, China, grant number was 2018 FB141.

Conflicts of Interest: The authors declare that they have no competing interests.

\section{Abbreviations}

$\mathrm{AD}$, Alzheimer's disease; $\mathrm{A} \beta$, amyloid beta; $\mathrm{BBB}$, blood-brain barrier; CNS, central nervous system; $\mathrm{HD}$, Huntington's disease; HIF- $1 \alpha$, hypoxia-inducible factor- $1 \alpha$; i.p., intraperitoneal injection; i.v., intravenous injection; $\mathrm{I} / \mathrm{R}$, ischemia-reperfusion injury; MCAO, middle cerebral artery occlusion; MPP+, 1-methyl-4-phenylpyridinium; MPTP, 1-methyl-4-phenyl-1,2,3,6-tetrahydropyridine; 3-NP, 3-nitropropionic acid; NSCs, neural stem cells; PD, Parkinson's disease; Rb1, ginsenoside Rb1; Rd, ginsenosides Rd; Rg1, ginsenoside Rg1; SN, substantia nigra; SNpc, substantia nigra pars compacta; SOD, superoxide dismutase; VEGF, vascular endothelial growth factor; PKA/CREB, hippocampal-dependent protein kinase/hippocampal-respond element-binding protein.

\section{References}

1. Liu, F.F.; Zhang, Z.; Chen, W.; Gu, H.Y.; Yan, Q.J. Regulatory mechanism of microRNA-377 on CDH13 expression in the cell model of Alzheimer's disease. Eur. Rev. Med. Pharmacol. Sci. 2018, 22, 2801-2808. [PubMed]

2. Zhong, L.L.; Song, Y.Q.; Cao, H.; Ju, K.J.; Yu, L. The non-motor symptoms of Parkinson's disease of different motor types in early stage. Eur. Rev. Med Pharmacol. Sci. 2017, 21, 5745-5750. [PubMed]

3. Baquero, M.; Martin, N. Depressive symptoms in neurodegenerative diseases. World J. Clin. Cases 2015, 3, 682-693. [CrossRef] [PubMed]

4. Moon, Y.; Sung, J.H.; An, R.; Hernandez, M.E.; Sosnoff, J.J. Gait variability in people with neurological disorders: A systematic review and meta-analysis. Hum. Mov. Sci. 2016, 47, 197-208. [CrossRef] [PubMed]

5. Buendia, I.; Michalska, P.; Navarro, E.; Gameiro, I.; Egea, J.; León, R. Nrf2-ARE pathway: An emerging target against oxidative stress and neuroinflammation in neurodegenerative diseases. Pharmacol. Ther. 2016, 157, 84-104. [CrossRef] [PubMed]

6. Ciechanover, A.; Kwon, Y.T. Degradation of misfolded proteins in neurodegenerative diseases: Therapeutic targets and strategies. Exp. Mol. Med. 2015, 47, e147. [CrossRef] [PubMed]

7. Kang, S.; Im, K.; Kim, G.; Min, H. Antiviral activity of 20(R)-ginsenoside Rh2 against murine gammaherpesvirus. J. Ginseng Res. 2017, 41, 496-502. [CrossRef]

8. Hong, B.N.; Ji, M.G.; Kang, T.H. The Efficacy of Red Ginseng in Type 1 and Type 2 Diabetes in Animals. Evid. Based Complement. Altern. Med. 2013, 2013, 593181. [CrossRef]

9. Jeong, C.S. Effect of butanol fraction of Panax ginseng head on gastric lesion and ulcer. Arch. Pharmacal. Res. 2002, 25, 61. [CrossRef]

10. Kiefer, D.; Pantuso, T. Panax ginseng. Am. Fam. Physician 2003, 68, 1539-1542.

11. Liu, X.; Wang, L.; Wen, A.; Yang, J.; Yan, Y.; Song, Y.; Liu, X.; Ren, H.; Wu, Y.; Li, Z.; et al. Ginsenoside-Rd improves outcome of acute ischaemic stroke-A randomized, double-blind, placebo-controlled, multicenter trial. Eur. J. Neurol. 2012, 19, 855-863. [CrossRef]

12. Strong, M.J.; Grace, G.M.; Freedman, M.; Lomen-Hoerth, C.; Woolley, S.; Goldstein, L.H.; Murphy, J.; Shoesmith, C.; Rosenfeld, J.; Leigh, P.N. Consensus criteria for the diagnosis of frontotemporal cognitive and behavioural syndromes in amyotrophic lateral sclerosis. Amyotroph. Lateral Scler. Mot. Neuron Disord. 2009, 10, 131-146. [CrossRef]

13. Wang, L.; Zhang, Y.; Wang, Z.; Li, S.; Min, G.; Wang, L.; Chen, J.; Cheng, J.; Wu, Y. Inhibitory effect of ginsenoside-Rd on carrageenan-induced inflammation in rats. Can. J. Physiol. Pharmacol. 2012, 90, 229-236. [CrossRef] 
14. Yang, X.L.; Guo, T.K.; Wang, Y.H.; Huang, Y.H.; Liu, X.; Wang, X.X.; Li, W.; Zhao, X.; Wang, L.P.; Yan, S. Ginsenoside Rd attenuates the inflammatory response via modulating p38 and JNK signaling pathways in rats with TNBS-induced relapsing colitis. Int. Immunopharmacol. 2012, 12, 408-414. [CrossRef]

15. Attele, A.S.; Wu, J.A.; Yuan, C.S. Ginseng pharmacology: Multiple constituents and multiple actions. Biochem. Pharmacol. 1999, 58, 1685-1693. [CrossRef]

16. Gillis, C.N. Panax ginseng pharmacology: A nitric oxide link? Biochem. Pharmacol. 1997, 54, 1-8. [CrossRef]

17. Peña, I.D.; Yoon, S.Y.; Kim, H.J.; Park, S.; Hong, E.Y.; Ryu, J.H.; Park, I.H.; Cheong, J.H. Effects of ginseol $\mathrm{k}$-g3, an Rg3-enriched fraction, on scopolamine-induced memory impairment and learning deficit in mice. J. Ginseng Res. 2014, 38, 1-7. [CrossRef]

18. Christensen, L.P. Chapter 1 Ginsenosides: Chemistry, Biosynthesis, Analysis, and Potential Health Effects. Adv. Food Nutr. Res. 2008, 55, 1-99.

19. Shin, B.K.; Kwon, S.W.; Park, J.H. Chemical diversity of ginseng saponins from Panax ginseng. J. Ginseng Res. 2015, 39, 287-298. [CrossRef]

20. Mancuso, C.; Santangelo, R. Panax ginseng and Panax quinquefolius: From pharmacology to toxicology. Food Chem. Toxicol. 2017, 107, 362-372. [CrossRef]

21. Kim, J.S.; Kim, Y.; Han, S.H.; Jeon, J.Y.; Hwang, M.; Im, Y.J.; Kim, J.H.; Sun, Y.L.; Chae, S.W.; Kim, M.G. Development and validation of an LC-MS/MS method for determination of compound $\mathrm{K}$ in human plasma and clinical application. J. Ginseng Res. 2013, 37, 135-141. [CrossRef]

22. Koh, E.; Jang, O.H.; Hwang, K.H.; An, Y.N.; Moon, B.K. Effects of Steaming and Air-Drying on Ginsenoside Composition of Korean Ginseng (Panax ginseng C.A. Meyer). J. Food Process. Preserv. 2015, 39, 207-213. [CrossRef]

23. Sun, Y.; Yue, L.; Chen, K. Roles and mechanisms of ginsenoside in cardiovascular diseases: Progress and perspectives. Sci. China Life Sci. 2016, 59, 292-298. [CrossRef]

24. Wang, Y.; Huang, C.; Zhang, H.; Wu, R. Autophagy in glaucoma: Crosstalk with apoptosis and its implications. Brain Res. Bull. 2015, 117, 1-9. [CrossRef]

25. Lee, B.; Sandhu, S.; McArthur, G. Cell cycle control as a promising target in melanoma. Curr. Opin. Oncol. 2015, 27, 141-150. [CrossRef]

26. Brassai, A.; Suvanjeiev, R.G.; Ban, E.G.; Lakatos, M. Role of synaptic and nonsynaptic glutamate receptors in ischaemia induced neurotoxicity. Brain Res. Bull. 2015, 112, 1-6. [CrossRef]

27. Dong, X.; Zheng, L.; Lu, S.; Yang, Y. Neuroprotective effects of pretreatment of ginsenoside Rb1 on severe cerebral ischemia-induced injuries in aged mice: Involvement of anti-oxidant signaling. Geriatr. Gerontol. Int. 2017, 17, 338-345. [CrossRef]

28. Lv, H.; Wang, L.; Shen, J.; Hao, S.; Ming, A.; Wang, X.; Su, F.; Zhang, Z. Salvianolic acid B attenuates apoptosis and inflammation via SIRT1 activation in experimental stroke rats. Brain Res. Bull. 2015, 115, 30-36. [CrossRef]

29. Liu, C.X.; Xiao, P.G. Recent advances on ginseng research in China. J. Ethnopharmacol. 1992, 36, $27-38$.

30. Nah, S.Y.; Park, H.J.; Mccleskey, E.W. A trace component of ginseng that inhibits Ca2+ channels through a pertussis toxin-sensitive G protein. Proc. Natl. Acad. Sci. USA 1995, 92, 8739-8743. [CrossRef]

31. Nocerino, E.; Amato, M.; Izzo, A.A. The aphrodisiac and adaptogenic properties of ginseng. Fitoterapia 2000, 71, S1-S5. [CrossRef]

32. Van, J.K.; Robertson, H.; Hagg, T.; Drobitch, R. Neuroprotective actions of the ginseng extract G115 in two rodent models of Parkinson's disease. Exp. Neurol. 2003, 184, 521-529.

33. Liu, L.; Anderson, G.A.; Fernandez, T.G.; Dore, S. Efficacy and Mechanism of Panax Ginseng in Experimental Stroke. Front. Neurosci. 2019, 13, 294. [CrossRef]

34. Gonzalez-Burgos, E.; Fernandez-Moriano, C.; Gomez-Serranillos, M.P. Potential neuroprotective activity of Ginseng in Parkinson's disease: A review. J. Neuroimmune Pharmacol. 2015, 10, 14-29. [CrossRef]

35. Razgonova, M.P.; Veselov, V.V.; Zakharenko, A.M.; Golokhvast, K.S.; Nosyrev, A.E.; Cravotto, G.; Tsatsakis, A.; Spandidos, D.A. Panax ginseng components and the pathogenesis of Alzheimer's disease (Review). Mol. Med. Rep. 2019, 19, 2975-2998. [CrossRef]

36. Kim, K.H.; Lee, D.; Lee, H.L.; Kim, C.E.; Jung, K.; Kang, K.S. Beneficial effects of Panax ginseng for the treatment and prevention of neurodegenerative diseases: Past findings and future directions. J. Ginseng Res. 2018, 42, 239-247. [CrossRef]

37. Rajabian, A.; Rameshrad, M.; Hosseinzadeh, H. Therapeutic potential of Panax ginseng and its constituents, ginsenosides and gintonin, in neurological and neurodegenerative disorders: A patent review. Expert Opin. Ther. Pat. 2018, 29, 55-72. [CrossRef] 
38. Mattson, M.P. Oxidative Stress, Perturbed Calcium Homeostasis, and Immune Dysfunction in Alzheimer's Disease. J. NeuroVirol. 2002, 8, 539-550. [CrossRef]

39. Harrop, J.S.; Sharan, A.D.; Vaccaro, A.R.; Przybylski, G.J. The cause of neurologic deterioration after acute cervical spinal cord injury. Spine 2001, 26, 340-346. [CrossRef]

40. Appel, S.H.; Smith, R.G.; Le, W.D. Immune-mediated cell death in neurodegenerative disease. Adv. Neurol. 1996, 69, 153-159.

41. Hardy, J. Pathways to Primary Neurodegenerative Disease. Ann. N. Y. Acad. Sci. 2000, 924, 29-34. [CrossRef]

42. Braak, H.; Tredici, K.D.; Rüb, U.; Vos, R.A.I.D.; Steur, E.N.H.J.; Braak, E. Staging of brain pathology related to sporadic Parkinson's disease. Neurobiol. Aging 2003, 24, 197-211. [CrossRef]

43. Hebert, L.E.; Jennifer, W.; Scherr, P.A.; Evans, D.A. Alzheimer disease in the United States (2010-2050) estimated using the 2010 census. Neurology 2013, 80, 1778-1783. [CrossRef]

44. Bolognin, S.; Blanchard, J.; Wang, X.; Basurtoislas, G.; Tung, Y.C.; Kohlbrenner, E.; Grundkeiqbal, I.; Iqbal, K. An experimental rat model of sporadic Alzheimer's disease and rescue of cognitive impairment with a neurotrophic peptide. Acta Neuropathol. 2012, 123, 133-151. [CrossRef]

45. Praticò, D. Oxidative stress hypothesis in Alzheimer's disease: A reappraisal. Trends Pharmacol. Sci. 2008, 29, 609-615. [CrossRef]

46. Li, N.; Liu, Y.; Li, W.; Zhou, L.; Li, Q.; Wang, X.; He, P. A UPLC/MS-based metabolomics investigation of the protective effect of ginsenosides Rg1 and Rg2 in mice with Alzheimer's disease. J. Ginseng Res. 2016, 40, 9-17. [CrossRef]

47. Li, N.; Liu, B.; Dluzen, D.E.; Jin, Y. Protective effects of ginsenoside Rg 2 against glutamate-induced neurotoxicity in PC12 cells. J. Ethnopharmacol. 2007, 111, 458-463. [CrossRef]

48. Liu, L.; Huang, J.; Hu, X.; Li, K.; Sun, C. Simultaneous determination of ginsenoside (G-Re, G-Rg1, G-Rg2, G-F1, G-Rh1) and protopanaxatriol in human plasma and urine by LC-MS/MS and its application in a pharmacokinetics study of G-Re in volunteers. J. Chromatogr. B Anal. Technol. Biomed. Life Sci. 2011, 879, 2011-2017. [CrossRef]

49. Jun, Y.E.; Yao, J.P.; Wang, X.U.; Zheng, M.; Peng, L.I.; Chengwei, H.E.; Wan, J.B.; Yao, X.; Huanxing, S.U. Neuroprotective effects of ginsenosides on neural progenitor cells against oxidative injury. Mol. Med. Rep. 2016, 13, 3083-3091.

50. Peng, L.H.; Ko, C.H.; Siu, S.W.; Koon, C.M.; Yue, G.L.; Cheng, W.H.; Lau, T.W.; Han, Q.B.; Ng, K.M.; Fung, K.P.; et al. In vitro \& in vivo assessment of a herbal formula used topically for bone fracture treatment. J. Ethnopharmacol. 2010, 131, 282-289.

51. Fang, F.; Chen, X.; Huang, T.; Lue, L.F.; Luddy, J.S.; Yan, S.S. Multi-faced neuroprotective effects of Ginsenoside Rg1 in an Alzheimer mouse model. Biochim. Biophys. Acta 2012, 1822, 286-292. [CrossRef]

52. Chen, X.M. Effect of Dosage Form and Administration Route to Distribution of Ginsenoside Rg1 in Serum and Brain of Rats. Chin. J. Exp. Tradit. Med Formulae 2011, 17, 43-46.

53. Bai-Yin, H.; Chang-Qing, L.; You-Liang, X.; Dong-Xu, J.; Jian-Nan, C.; Fang-Yi, L. Study on percutaneous absorption of ginsenoside Rg1 in total saponins from Panax notoginseng through intact skin. J. Guangdong Pharm. Coll. 2010, 26, 564-567.

54. Jia, L.; Wei, C.; Zi-Min, Y.; Xue-Tao, L. In vitro transdermal absorption studies of ginsenoside Rg1 in traumatology spray. Chin. J. Exp. Tradit. Chin. Med. 2010, 18, 18-20.

55. Yuan, S.; Bo, L.; Xiu-Mei, T. Experimental study on in vitro permeation of swollen and painful cataplasm. Yunnan J. Tradit. Chin. Med. 2012, 33, 54.

56. Hong-Cai, W.; Yu-Meng, J.; Xue, Z.; Ning, W.; Di, G.; Ming, G.; Jing-Yu, Z.; Zi-Chao, Y. Protective effects of ginsenoside $\mathrm{Rb} 1$ on $\mathrm{A} \beta$ amyloid-induced hippocampal neuronal injury in rats. J. Jilin Univ. Med. Ed. 2012, 38, 447-450.

57. Zhao, H.H.; Di, J.; Liu, W.S.; Liu, H.L.; Lai, H.; Lu, Y.L. Involvement of GSK3 and PP2A in ginsenoside Rb1's attenuation of aluminum-induced tau hyperphosphorylation. Behav. Brain Res. 2013, 241, 228-234. [CrossRef]

58. Schapira, A.H. Pathogenesis of Parkinson's disease. Baillières Clin. Neurol. 2011, 258, 307-310.

59. Lees, A.J.; Hardy, J.; Revesz, T. Parkinson's disease. Lancet 2009, 373, 2055-2066. [CrossRef]

60. Badger, J.L.; Corderollana, O.; Hartfield, E.M.; Wademartins, R. Parkinson's disease in a dish-Using stem cells as a molecular tool. Neuropharmacology 2014, 76, 88-96. [CrossRef] 
61. Kim, D.; Jeon, H.; Ryu, S.; Koo, S.; Ha, K.T.; Kim, S. Proteomic Analysis of the Effect of Korean Red Ginseng in the Striatum of a Parkinson's Disease Mouse Model. PLoS ONE 2016, 11, e0164906. [CrossRef]

62. Zhou, T.; Zu, G.; Zhang, X.; Wang, X.; Li, S.; Gong, X.; Liang, Z.; Zhao, J. Neuroprotective effects of ginsenoside Rg1 through the Wnt/beta-catenin signaling pathway in both in vivo and in vitro models of Parkinson's disease. Neuropharmacology 2016, 101, 480-489. [CrossRef]

63. Ardah, M.T.; Paleologou, K.E.; Lv, G.; Menon, S.A.; Abul Khair, S.B.; Lu, J.H.; Safieh-Garabedian, B.; Al-Hayani, A.A.; Eliezer, D.; Li, M.; et al. Ginsenoside Rb1 inhibits fibrillation and toxicity of alpha-synuclein and disaggregates preformed fibrils. Neurobiol. Dis. 2015, 74, 89-101. [CrossRef]

64. Radad, K.; Gille, G.; Moldzio, R.; Saito, H.; Ishige, K.; Rausch, W.D. Ginsenosides Rb1 and Rg1 effects on survival and neurite growth of MPP+-affected mesencephalic dopaminergic cells. J. Neural Transm. 2004, 111, 37-45. [CrossRef]

65. Heng, Y.; Zhang, Q.S.; Mu, Z.; Hu, J.F.; Yuan, Y.H.; Chen, N.H. Ginsenoside Rg1 attenuates motor impairment and neuroinflammation in the MPTP-probenecid-induced parkinsonism mouse model by targeting alpha-synuclein abnormalities in the substantia nigra. Toxicol. Lett. 2016, 243, 7-21. [CrossRef]

66. Zhou, T.T.; Zu, G.; Wang, X.; Zhang, X.G.; Li, S.; Liang, Z.H.; Zhao, J. Immunomodulatory and neuroprotective effects of ginsenoside Rg1 in the MPTP(1-methyl-4-phenyl-1,2,3,6-tetrahydropyridine) -induced mouse model of Parkinson's disease. Int. Immunopharmacol. 2015, 29, 334-343. [CrossRef]

67. Chen, C.; Wang, L.; Cao, F.; Miao, X.; Chen, T.; Chang, Q.; Zheng, Y. Formulation of 20(S)-protopanaxadiol nanocrystals to improve oral bioavailability and brain delivery. Int. J. Pharm. 2016, 497, 239-247. [CrossRef]

68. Sun, X.C.; Ren, X.F.; Chen, L.; Gao, X.Q.; Xie, J.X.; Chen, W.F. Glucocorticoid receptor is involved in the neuroprotective effect of ginsenoside $\operatorname{Rg} 1$ against inflammation-induced dopaminergic neuronal degeneration in substantia nigra. J. Steroid Biochem. Mol. Biol. 2016, 155, 94-103. [CrossRef]

69. Khadrawy, Y.A.; Mourad, I.M.; Mohammed, H.S.; Noor, N.A.; Ezz, H.S.A. A study on the possible therapeutic role of Panax ginseng extract against a rat model of Parkinson's disease induced by intrastriatal rotenone injection. Int. J. Clin. Exp. Med. 2016, 9, 3831-3841.

70. Chen, X.; Huang, T.; Zhang, J.; Song, J.; Chen, L.; Zhu, Y. Involvement of calpain and p25 of CDK5 pathway in ginsenoside Rb1's attenuation of beta-amyloid peptide25-35-induced tau hyperphosphorylation in cortical neurons. Brain Res. 2008, 1200, 99-106. [CrossRef]

71. Chong, M.S.; Goh, L.K.; Lim, W.S.; Chan, M.; Tay, L.; Chen, G.; Feng, L.; Ng, T.P.; Tan, C.H.; Lee, T.S. Gene expression profiling of peripheral blood leukocytes shows consistent longitudinal downregulation of TOMM40 and upregulation of KIR2DL5A, PLOD1, and SLC2A8 among fast progressors in early Alzheimer's disease. J. Alzheimer's Dis. JAD 2013, 34, 399-405. [CrossRef]

72. Hwang, J.Y.; Shim, J.S.; Song, M.Y.; Yim, S.V.; Lee, S.E.; Park, K.S. Proteomic analysis reveals that the protective effects of ginsenoside $\mathrm{Rb} 1$ are associated with the actin cytoskeleton in beta-amyloid-treated neuronal cells. J. Ginseng Res. 2016, 40, 278-284. [CrossRef]

73. Zhao, H.; Li, Q.; Zhang, Z.; Pei, X.; Wang, J.; Li, Y. Long-term ginsenoside consumption prevents memory loss in aged SAMP8 mice by decreasing oxidative stress and up-regulating the plasticity-related proteins in hippocampus. Brain Res. 2009, 1256, 111-122. [CrossRef]

74. Baake, V.; Reijntjes, R.; Dumas, E.M.; Thompson, J.C.; Roos, R.A.C.; REGISTRY Investigators of the European Huntington's Disease Network. Cognitive decline in Huntington's disease expansion gene carriers. Cortex 2017, 95, 51-62. [CrossRef]

75. Mehrabi, N.F.; Waldvogel, H.J.; Tippett, L.J.; Hogg, V.M.; Synek, B.J.; Faull, R.L. Symptom heterogeneity in Huntington's disease correlates with neuronal degeneration in the cerebral cortex. Neurobiol. Dis. 2016, 96, 67-74. [CrossRef]

76. Rosas, H.D.; Salat, D.H.; Lee, S.Y.; Zaleta, A.K.; Hevelone, N.; Hersch, S.M. Complexity and Heterogeneity: What Drives the Ever-changing Brain in Huntington's Disease? Ann. N. Y. Acad. Sci. 2008, 1147, 196-205. [CrossRef]

77. Waldvogel, H.J.; Thu, D.; Hogg, V.; Tippett, L.; Faull, R.L.M. Selective neurodegeneration, neuropathology and symptom profiles in Huntington's disease. Adv. Exp. Med. Biol. 2012, 769, 141-152.

78. Wu, J.; Jeong, H.K.; Bulin, S.E.; Kwon, S.W.; Park, J.H.; Bezprozvanny, I. Ginsenosides protect striatal neurons in a cellular model of Huntington's disease. J. Neurosci. Res. 2009, 87, 1904-1912. [CrossRef] 
79. Kim, J.H.; Kim, S.; Yoon, I.S.; Lee, J.H.; Jang, B.J.; Jeong, S.M.; Lee, J.H.; Lee, B.H.; Han, J.S.; Oh, S.; et al. Protective effects of ginseng saponins on 3-nitropropionic acid-induced striatal degeneration in rats. Neuropharmacology 2005, 48, 743-756. [CrossRef]

80. Johnston, S.C.; Mendis, S.; Mathers, C.D. Global variation in stroke burden and mortality: Estimates from monitoring, surveillance, and modelling. Lancet Neurol. 2009, 8, 345-354. [CrossRef]

81. Woodruff, T.M.; Thundyil, J.; Tang, S.C.; Sobey, C.G.; Taylor, S.M.; Arumugam, T.V. Pathophysiology, treatment, and animal and cellular models of human ischemic stroke. Mol. Neurodegener. 2011, 6, 11. [CrossRef]

82. Gomes, J.; Wachsman, A.M. Types of Strokes. In Handbook of Clinical Nutrition and Stroke; Humana Press: Totowa, NJ, USA, 2013; pp. 15-31.

83. Callahan, A.; Amarenco, P.; Goldstein, L.B.; Sillesen, H.; Messig, M.; Samsa, G.P.; Altafullah, I.; Ledbetter, L.Y.; Macleod, M.J.; Scott, R. Risk of Stroke and Cardiovascular Events After Ischemic Stroke or Transient Ischemic Attack in Patients With Type 2 Diabetes or Metabolic Syndrome: Secondary Analysis of the Stroke Prevention by Aggressive Reduction in Cholesterol Levels (SPARCL) Trial. Arch. Neurol. 2011, 68, 1245-1251. [CrossRef]

84. Zheng, G.Q.; Cheng, W.; Wang, Y.; Wang, X.M.; Zhao, S.Z.; Zhou, Y.; Liu, S.J.; Wang, X.T. Ginseng total saponins enhance neurogenesis after focal cerebral ischemia. J. Ethnopharmacol. 2011, 133, 724-728. [CrossRef]

85. Liu, X.; Xia, J.; Wang, L.; Song, Y.; Yang, J.; Yan, Y.; Ren, H.; Zhao, G. Efficacy and safety of ginsenoside-Rd for acute ischaemic stroke: A randomized, double-blind, placebo-controlled, phase II multicenter trial. Eur. J. Neurol. 2009, 16, 569-575. [CrossRef]

86. Sutherland, B.A.; Minnerup, J.; Balami, J.S.; Arba, F.; Buchan, A.M.; Kleinschnitz, C. Neuroprotection for ischaemic stroke: Translation from the bench to the bedside. Int. J. Stroke 2012, 7, 407-418. [CrossRef]

87. Wahlgren, N.G.; Ahmed, N. Neuroprotection in cerebral ischaemia: Facts and fancies-the need for new approaches. Cerebrovasc. Dis. 2004, 17, 153-166. [CrossRef]

88. Yoshikawa, T.; Akiyoshi, Y.; Susumu, T.; Tokado, H.; Fukuzaki, K.; Nagata, R.; Samukawa, K.; Iwao, H.; Kito, G. Ginsenoside Rb1 Reduces Neurodegeneration in the Peri-infarct Area of a Thromboembolic Stroke Model in Non-human Primates. J. Pharmacol. Sci. 2008, 107, 32-40. [CrossRef]

89. Li, Y.; Tang, J.; Khatibi, N.H.; Zhu, M.; Chen, D.; Tu, L.; Chen, L.; Wang, S. Treatment with ginsenoside rb1, a component of panax ginseng, provides neuroprotection in rats subjected to subarachnoid hemorrhage-induced brain injury. Acta Neurochir. Suppl. 2011, 110, 75-79.

90. Jiang, Z.; Wang, Y.; Zhang, X.; Peng, T.; Lu, Y.; Leng, J.; Xie, Q. Preventive and therapeutic effects of ginsenoside $\mathrm{Rb} 1$ for neural injury during cerebral infarction in rats. Am. J. Chin. Med. 2013, 41, 341-352. [CrossRef]

91. Wan, F.; Si, Y.C.; Niu, X. Effects of astrocyte following treatment with ginsenoside on proliferation and differentiation of neural stem cells after stroke. China J. Tradit. Chin. Med. Pharm. 2016, 5, 1617-1624.

92. Chen, J.; Bai, Q.; Zhao, Z.; Sui, H.; Xie, X. Ginsenoside Represses Symptomatic Intracerebral Hemorrhage after Recombinant Tissue Plasminogen Activator Therapy by Promoting Transforming Growth Factor-beta1. J. Stroke Cerebrovasc. Dis. 2016, 25, 549-555. [CrossRef]

93. Tuttolomondo, A.; Sciacca, R.D.; Raimondo, D.D.; Pedone, C.; Placa, S.L.; Pinto, A.; Licata, G. Effects of clinical and laboratory variables and of pretreatment with cardiovascular drugs in acute ischaemic stroke: A retrospective chart review from the GIFA study. Int. J. Cardiol. 2011, 151, 318-322. [CrossRef]

94. Guo, Z.; Cao, G.; Yang, H.; Zhou, H.; Li, L.; Cao, Z.; Yu, B.; Kou, J. A combination of four active compounds alleviates cerebral ischemia-reperfusion injury in correlation with inhibition of autophagy and modulation of AMPK/mTOR and JNK pathways. J. Neurosci. Res. 2014, 92, 1295-1306. [CrossRef]

95. Gao, X.Q.; Yang, C.X.; Chen, G.J.; Wang, G.Y.; Chen, B.; Tan, S.K.; Liu, J.; Yuan, Q.L. Ginsenoside Rb1 regulates the expressions of brain-derived neurotrophic factor and caspase-3 and induces neurogenesis in rats with experimental cerebral ischemia. J. Ethnopharmacol. 2010, 132, 393-399. [CrossRef]

96. Rui, W.; Li, Y.N.; Wang, G.J.; Hao, H.P.; Wu, X.L.; Fang, Z. Neuroprotective effects and brain transport of ginsenoside Rg1. Chin. J. Nat. Med. 2009, 7, 315-320.

97. Sierra, C.; Coca, A.; Schiffrin, E.L. Vascular mechanisms in the pathogenesis of stroke. Curr. Hypertens. Rep. 2011, 13, 200-207. [CrossRef]

98. Allen, C.L.; Bayraktutan, U. Oxidative stress and its role in the pathogenesis of ischaemic stroke. Int. J. Stroke 2009, 4, 461-470. [CrossRef]

99. Kim, J.S.; Yun, I.; Choi, Y.B.; Lee, K.S.; Kim, Y.I. Ramipril protects from free radical induced white matter damage in chronic hypoperfusion in the rat. J. Clin. Neurosci. 2008, 15, 174-178. [CrossRef] 
100. Sun, Z.G.; Chen, L.P.; Wang, F.W.; Xu, C.Y.; Geng, M. Protective effects of ginsenoside Rg1 against hydrogen peroxide-induced injur y in human neuroblastoma cells. Neural Regen. Res. 2016, 11, 1159-1164.

101. Xie, Z.; Shi, M.; Zhang, C.; Zhao, H.; Hui, H.; Zhao, G. Ginsenoside Rd Protects Against Cerebral Ischemia-Reperfusion Injury Via Decreasing the Expression of the NMDA Receptor 2B Subunit and its Phosphorylated Product. Neurochem. Res. 2016, 41, 2149-2159. [CrossRef]

102. Xie, C.L.; Li, J.H.; Wang, W.W.; Zheng, G.Q.; Wang, L.X. Neuroprotective effect of ginsenoside-Rg1 on cerebral ischemia/reperfusion injury in rats by downregulating protease-activated receptor-1 expression. Life Sci. 2015, 121, 145-151. [CrossRef]

103. Zhang, Y.F.; Fan, X.J.; Li, X.; Peng, L.L.; Wang, G.H.; Ke, K.F.; Jiang, Z.L. Ginsenoside Rg1 protects neurons from hypoxic-ischemic injury possibly by inhibiting $\mathrm{Ca}^{2+}$ influx through NMDA receptors and L-type voltage-dependent $\mathrm{Ca}^{2+}$ channels. Eur. J. Pharmacol. 2008, 586, 90-99. [CrossRef]

104. Ye, R.; Kong, X.; Yang, Q.; Zhang, Y.; Han, J.; Li, P.; Xiong, L.; Zhao, G. Ginsenoside rd in experimental stroke: Superior neuroprotective efficacy with a wide therapeutic window. Neurotherapeutics 2011, 8, 515-525. [CrossRef]

105. Ye, R.; Kong, X.; Yang, Q.; Zhang, Y.; Han, J.; Zhao, G. Ginsenoside Rd attenuates redox imbalance and improves stroke outcome after focal cerebral ischemia in aged mice. Neuropharmacology 2011, 61, 815-824. [CrossRef]

106. Ye, R.; Zhang, X.; Kong, X.; Han, J.; Yang, Q.; Zhang, Y.; Chen, Y.; Li, P.; Liu, J.; Shi, M.; et al. Ginsenoside Rd attenuates mitochondrial dysfunction and sequential apoptosis after transient focal ischemia. Neuroscience 2011, 178, 169-180. [CrossRef]

107. Ye, R.; Yang, Q.; Kong, X.; Han, J.; Zhang, X.; Zhang, Y.; Li, P.; Liu, J.; Shi, M.; Xiong, L.; et al. Ginsenoside Rd attenuates early oxidative damage and sequential inflammatory response after transient focal ischemia in rats. Neurochem. Int. 2011, 58, 391-398. [CrossRef]

108. Ye, R.; Li, N.; Han, J.; Kong, X.; Cao, R.; Rao, Z.; Zhao, G. Neuroprotective effects of ginsenoside Rd against oxygen-glucose deprivation in cultured hippocampal neurons. Neurosci. Res. 2009, 64, 306-310. [CrossRef]

109. Strunk, D.R.; Adler, A.D.; Hollars, S.N. Cognitive Therapy Skills Predict Cognitive Reactivity to Sad Mood Following Cognitive Therapy of Depression. Cognitive Ther. Res. 2013, 37, 1214-1219. [CrossRef]

110. Harzheim, D.; Klose, H.; Pinado, F.P.; Ehlken, N.; Nagel, C.; Fischer, C.; Ghofrani, A.; Rosenkranz, S.; Seyfarth, H.J.; Halank, M. Anxiety and depression disorders in patients with pulmonary arterial hypertension and chronic thromboembolic pulmonary hypertension. Respir. Res. 2013, 14, 104. [CrossRef]

111. Jin, C.; Wang, Z.Z.; Zhou, H.; Lou, Y.X.; Chen, J.; Zuo, W.; Tian, M.T.; Wang, Z.Q.; Du, G.H.; Kawahata, I.; et al. Ginsenoside Rg1-induced antidepressant effects involve the protection of astrocyte gap junctions within the prefrontal cortex. Prog. Neuro Psychopharmacol. Biol. Psychiatry 2017, 75, 183-191. [CrossRef]

112. Jeong, H.G.; Ko, Y.H.; Oh, S.Y.; Han, C.; Kim, T.; Joe, S.H. Effect of Korean Red Ginseng as an adjuvant treatment for women with residual symptoms of major depression. Asia Pac. Psychiatry 2015, 7, 330-336. [CrossRef]

113. Lee, K.J.; Ji, G.E. The effect of fermented red ginseng on depression is mediated by lipids. Nutr. Neurosci. 2014, 17, 7-15. [CrossRef]

114. Kim, M.; Kim, S.O.; Lee, M.; Park, Y.; Kim, D.; Cho, K.H.; Kim, S.Y.; Lee, E.H. Effects of ginsenoside Rb1 on the stress-induced changes of BDNF and HSP70 expression in rat hippocampus. Environ. Toxicol. Pharmacol. 2014, 38, 257-262. [CrossRef]

115. Sang, H.L.; Jung, B.H.; Sang, Y.C.; Sun, Y.K.; Lee, E.H.; Chung, B.C. Influence of ginsenoside Rb1 on brain neurosteroid during acute immobilization stress. Arch. Pharmacal. Res. 2006, 29, 566-569.

116. Lee, S.H.; Jung, B.H.; Kim, S.Y.; Lee, E.H.; Chung, B.C. The antistress effect of ginseng total saponin and ginsenoside $\mathrm{Rg} 3$ and $\mathrm{Rb} 1$ evaluated by brain polyamine level under immobilization stress. Pharmacol. Res. 2006, 54, 46-49. [CrossRef]

117. Sang, H.L.; Hur, J.; Lee, E.H.; Sun, Y.K. Ginsenoside Rb1 Modulates Level of Monoamine Neurotransmitters in Mice Frontal Cortex and Cerebellum in Response to Immobilization Stress. Biomol. Ther. 2012, 20, 482-486.

118. Jia, D.Y.; Zhang, M.X.; Yao, Y.R.; Jin, W.; Liu, J.W.; Wang, J.L.; Chen, B.C. Effects of ginsenoside Rb1 on the mRNA expression of tyrosine kinase B in the hippocampus of acute immobilization stress rats. Chin. J. Integr. Tradit. West. Med. 2013, 33, 376-379.

119. Dong, J.; Wang, J.; Fang, J.; Feng, R.; Yuan, Z.; Lu, K.; Jin, Y.; Zeng, L. Effects of ginsenosides Rb1 on learning and memory and expression of somatostatin in sleep deprivation rats. J. Zhejiang Univ. 2013, 42, 197-204. 
120. Liang, J.; Yu, Y.; Wang, B.; Lu, B.; Zhang, J.; Zhang, H.; Ge, P. Ginsenoside Rb1 attenuates oxygen-glucose deprivation-induced apoptosis in SH-SY5Y cells via protection of mitochondria and inhibition of AIF and cytochrome c release. Molecules 2013, 18, 12777-12792. [CrossRef]

121. Wu, H.T.; Chen, X.X.; Xiong, L.J. Experimental study of proliferation of schwann cells cultured with ginsenoside rb_1. Chin. J. Repar. Reconstr. Surg. 2003, 17, 26-29.

(C) 2019 by the authors. Licensee MDPI, Basel, Switzerland. This article is an open access article distributed under the terms and conditions of the Creative Commons Attribution (CC BY) license (http://creativecommons.org/licenses/by/4.0/). 